\section{Salivary nitrite and systemic biomarkers in obese individuals with periodontitis submitted to FMD}

Sheila C Cortelli 101 ; Priscila de Macedo Máximo ${ }^{1}$; Felipe S Peralta ${ }^{1}$; Rodrigo Augusto da Silva 1; Emanuel S Rovai 1; Fernando 0 Costa 2; Davi R Aquino 1; Edson Rodrigues ${ }^{3}$; Jose R Cortelli (ib 1

The objective of this 9-month clinical study is to assess the impact of onestage full-mouth disinfection (FMD) on salivary nitrite levels and systemic biomarkers and its correlation with total subgingival bacterial load in obese and non-obese patients with periodontitis. In total, 94 patients (55 obese and 39 non-obese) were initially evaluated, seven were lost during follow-up, resulting in 87 individuals at the end of the study. Outcomes were assessed at baseline, 3, 6, and 9 months post periodontal treatment by FMD. Salivary nitrite levels were determined using Griess reagent. Blood samples were collected to determine C-Reactive Protein (CRP), alkaline phosphatase and fasting blood glucose. Real-time PCR was used to determine the total subgingival bacterial load. FMD protocol resulted in increased salivary nitrite levels at $6-$ and 9-months post-treatment in the non-obese group $(p<0.05)$. In obese individuals, FMD treatment led to an increase in salivary nitrite levels at 6 months $(p<0.05)$; however, at 9 months, the nitrite levels returned to baseline levels. For both groups, the highest nitrite values were observed at 6 months. In addition, in both groups, FMD was associated with a decrease in biomarkers related to systemic inflammation and cardiovascular diseases, such as CRP $(p<0.05)$ and alkaline phosphatase $(p<0.05)$, and had no impact on the fasting blood glucose. This study demonstrates that obese patients with periodontitis present similar salivary nitrite levels when compared with non-obese individuals. FMD protocol resulted in increases in salivary nitrite levels and was associated with a positive impact on systemic biomarkers, regardless of obesity status.

\author{
${ }^{1}$ Department of Dentistry, Periodontics \\ Research Division, University of Taubaté, \\ Taubaté, São Paulo, Brazil. \\ ${ }^{2}$ School of Dentistry, Department of \\ Periodontology, Federal University of Minas \\ Gerais, Brazil ${ }^{3}$
}

${ }^{3}$ Institute of Bioscience, Biochemistry Division, University of Taubaté, Taubaté, São Paulo, Brazil

Correspondence: Emanuel Silva Rovai Department of Dentistry, Periodontics Research Division, University of Taubaté, Taubaté, São Paulo, Brazil. R. dos Operários, 09 - Centro, Taubaté - SP, 12020-340, Brazil Phone: +55 12 3625-4149

E-mail: Emanuel.rovai@hotmail.com

Keywords: Obesity, Nitrites; Bacteria; Periodontal diseases; Therapeutics.

\title{
Introduction
}

Periodontitis is a chronic multifactorial inflammatory disease associated with dysbiotic biofilms, that results in the destruction of tooth support tissues and, consequently, tooth loss (1). Biofilm is not solely sufficient to cause periodontal tissue breakdown, leading researchers to become interested in host immune-related factors (2).

Among the host immune-related factors, the free radical nitric oxide (NO) may play an important role in destabilizing the balance between microorganisms and inflammatory responses (3). NO can have both antimicrobial and cytotoxic effects, playing positive and negative roles in periodontal disease, respectively (4). However, due to its high volatility in human fluids, including saliva, studies have used the nitrite metabolized by oral-facultative anaerobic bacteria as an intermediate. These microorganisms use salivary nitrate as an alternative electron acceptor for oxygen during respiration and, after being reduced by nitrate reductases, produce a significant concentration of bodily nitrite $(5,6)$. The relationship between salivary nitrite/nitrate levels and periodontal diseases remains controversial. While some studies have found greater salivary nitrite concentrations in patients with periodontitis than in healthy controls $(7,8)$, others have not $(9,10)$. Studies on the effect of periodontal treatment on salivary nitrite concentration further highlight this discrepancy $(7,11,12)$.

Nitrite has also been implicated in several systemic physiological effects such as vasodilation, glycemic control, and blood pressure regulation $(13,14)$. A decrease in oral bacteria, and thus the nitrate-nitrite-nitric oxide cycle, by chlorhexidine mouthwash has been associated with an increased risk for systemic disorders, such as cardiovascular disease and insulin resistance 
$(14,15)$. A 3-year longitudinal study found that obese individuals using mouthwash twice daily were $\sim 50 \%$ more likely to develop hypertension and either diabetes or prediabetes; however, it is important to highlight that this study did not correlate oral bacteria with nitrite levels (16).

Since obesity increases an individual's risk for various nitrite-linked systemic disorders, it is important to understand whether nitrite levels correlate to periodontal disease and disproportionately interfere with the health of obese individuals.

Periodontal treatment through full-mouth disinfection (FMD) as described by Quirynen et al. 1995, (18) consists of full-mouth scaling and an extensive disinfection of oral tissues with chlorhexidine, including the use of $0.12 \%$ chlorhexidine mouthwash twice-daily for 2 weeks. This study aims to evaluate the impact of periodontal treatment by FMD protocol on salivary nitrite concentrations and systemic biomarkers related to cardiovascular disease and glycemic control, in obese and non-obese periodontitis patients.

\section{Material and Methods}

This study presents the salivary nitrite and systemic biomarkers data of a 9-month, parallel group, clinical study.

The study was approved by the University of Taubate, São Paulo, Brazil ethics committee, under protocol \# 36828114.4.0000.5501 and was conducted in accordance with the Helsinki Declaration of 1975, as revised in 2013. All participants provided written informed consent before enrolling in this clinical study. This protocol was registered at Clinicaltrials.gov (NCT03103204).

\section{Study population}

A total of 94 patients with periodontitis referred to the Center for Dental Specialties of Joinville-SC were included. All individuals presented moderate to severe generalized periodontitis (stage II-IV) according to the new classification of periodontal disease(18).

Inclusion criteria were as follows: $\geq 45$ years old, at least 12 natural teeth, body mass index (BMI) $>18.5 \mathrm{~kg} / \mathrm{m} 2$. Patients were excluded if they presented orthodontic devices; systemic diseases or conditions that could impact the periodontal status (other than diabetes); pregnancy or breastfeeding; alcohol abuse; medical conditions requiring prophylactic antibiotic coverage; use of systemic antibiotics and/or anti-inflammatory drugs in the 6 months prior to this study; and had a history of periodontal therapy within 6 months of this study.

\section{Experimental design and treatment protocol}

This was a 9-months clinical study where participants were divided into two groups: Nonobese group, $n=39$; and Obese group, $n=55$.

Periodontal clinical exams and treatment were carried out by a periodontist (F.S.P), previously calibrated and trained by a gold-standard examiner (J.R.C.) The calibration was carried out by the standard error of measurement (SEm) system in order to determine intra-examiner reproducibility. The training and calibration process followed the method described by Araujo et al. (19). The examiner was considered calibrated when a value of SEM $\leq 0.8$ was obtained. The degree of reliability of the intra-examiner analysis was SEm $=0.0944$.

Initially, all patients underwent oral hygiene instructions; subsequently, FMD therapeutic protocol was performed as described by Quirynen et al. 1995 (18). This consisted of a full-mouth periodontal debridement within 24 hours in two, 1-hour sessions. This was followed by tongue brushing with 1\% chlorhexidine gel for 1-minute, subgingival irrigation with 1\% chlorhexidine gel after scaling, and mouthwashes with $0.12 \%$ chlorhexidine for 30 seconds at the beginning and end of each session. The last 10 seconds of treatment involved gargling. In addition, $0.12 \%$ chlorhexidine was used twice-daily for 14 days.

\section{Anthropometric measurements}

Height, waist circumference, and weight were recorded at the beginning of the study. Obesity was defined as BMI $\geq 30 \mathrm{~kg} / \mathrm{m} 2$ and calculated by dividing the individual's weight (kg) by their height (m2). In addition, the following waist circumference values were referenced to indicate obesity: $>102 \mathrm{~cm}$ for men and $>88 \mathrm{~cm}$ for women (WHO, 2008). 


\section{Systemic biomarkers}

Ten $\mathrm{mL}$ of peripheral blood were collected by nurse staff at the Health Unit - PAM Bucarein, Center of Dental Specialties to determine levels of C-reactive Protein (CRP), Alkaline phosphatase and fasting blood glucose at baseline and at 3, 6, and 9 months post therapy. Samples were processed and analyzed at the Joinville municipal laboratory.

\section{Salivary sampling}

Saliva samples were collected in the morning, from 08:00-11:00 AM, at baseline and at 3, 6 , and 9 months post therapy. All individuals were instructed not to eat or drink prior to sampling. On the day of collection, individuals rinsed their mouths with water. During collection, patients were asked to remain seated with their heads tilted forward at a $\sim 45^{\circ}$ angle and. $2.0 \mathrm{~mL}$ of unstimulated saliva was collected into sterile Falcon tubes and centrifuged for 10 min at 15,000 $\times \mathrm{g}$ at $4^{\circ} \mathrm{C}$. Supernatants were transferred into sterile and coded Eppendorf tubes and stored at $-80^{\circ} \mathrm{C}$.

\section{Nitrite analyses}

Griess assay was used to determine salivary nitrite concentration at baseline and at 3, 6, and 9 months post therapy, as described by Cortelli et al. 2015 (11). All sampling and laboratorial procedures were performed by personnel (SCC, ER) who were blinded into groups.

\section{Microbiological monitoring}

Subgingival samples were collected as described in our previous study (11). The total bacterial load was assessed using quantitative real-time polymerase chain reaction (qPCR) using a TaqMan (Life Technology, Carlsbad, CA, USA) assay with specific set of primer/probes in Real-Time PCR System, following the manufacturer's instructions. A software online version was used in order to design the following primer/probe: Universal (forward: TGG AGC ATG TGG TTT AAT TCG A; reverse: TGC GGG ACT TAA CCC AAC A; probe: VICCAC GAG CTG ACG ACA AGC CAT GCATAMRA). Primer/Probe specificity was tested using the NCBI Blast database. The qPCR conditions included $500 \mathrm{C}$ for $2 \mathrm{~min}, 950 \mathrm{C}$ for $10 \mathrm{~min}, 40$ cycles of $950 \mathrm{C}$ for $15 \mathrm{~s}$, and $60 \mathrm{oC}$ for 1 $\min$.

\section{Statistical analysis}

For sample size calculation, we selected by simple randomization the data of salivary nitrite levels from five individuals. With the aid of biostat 5.2 software, a t-test with 95\% significance and 90\% power was applied for independent samples. Assuming a 20\% dropout, the statistical demand required a minimum of 35 individuals in each group.

All data from the present study were submitted to the Kolmorogov-Smirnov normality test. Nitrite levels and systemic biomarkers were compared over time using Friedman and analysis of variance (ANOVA) tests. Dichotomous sociodemographic variables were assessed by Fisher exact test and chi-square. In order to assess the relation between nitrite and other variables, the Spearman correlation test was used. Standard error (SE) was provided to demonstrate how close our sample mean was to the population mean. All analyses were performed using the GraphPad software (GraphPad Software, La Jolla, CA, USA) with an $\alpha$ of 5\%.

\section{Results}

Ninety-four individuals were evaluated at baseline. Five individuals in the obese group and 2 in the non-obese group were eliminated from the study, as they did not attend the follow-up visits (Figure 1). 


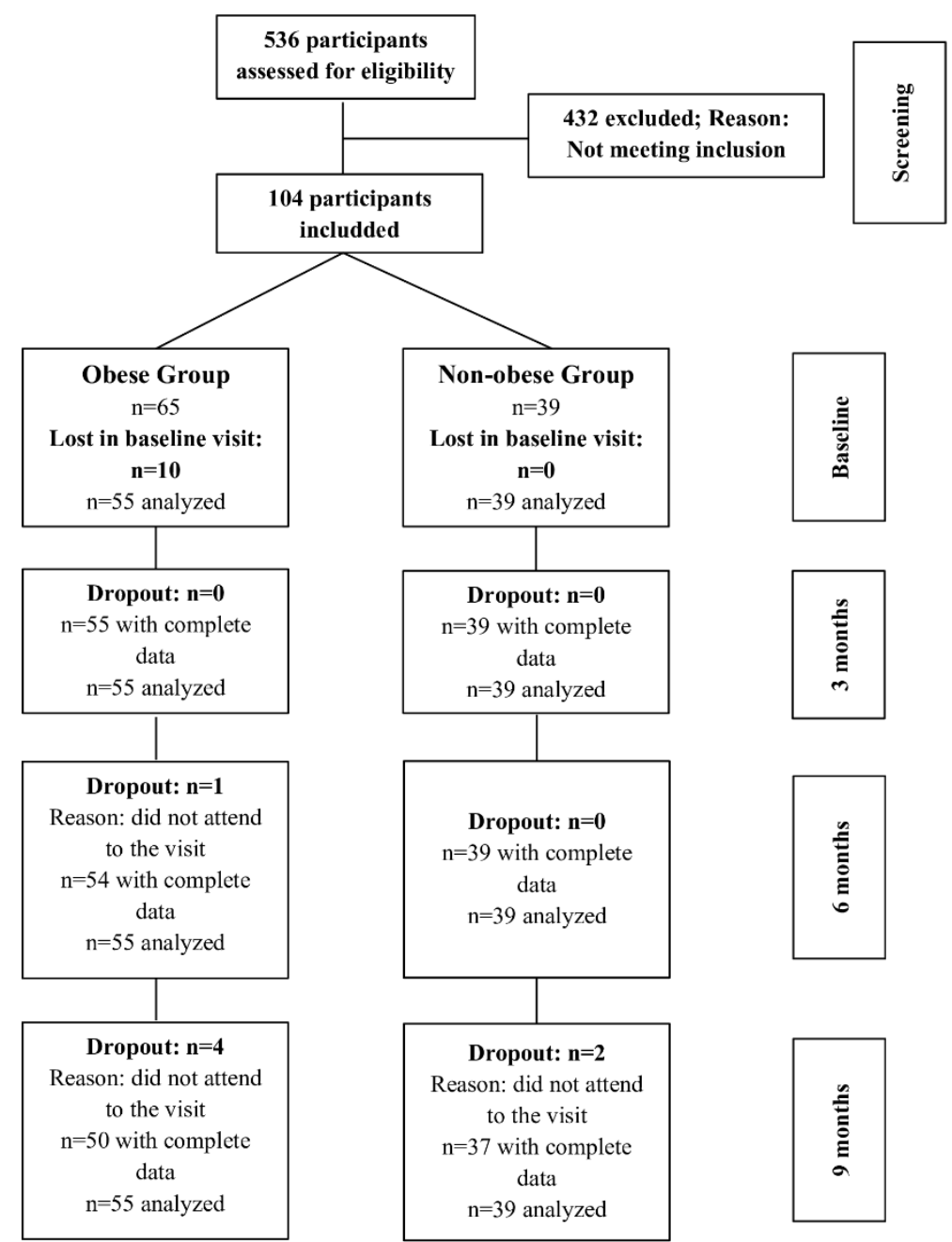

Figure 1. Flow chart of the study.

Groups were homogeneous with regards to sex, ethnicity, diabetic condition, and smoking habits ( $>0.05)$; however, arterial hypertension was more prevalent in the obese group $(p<0.05)$. The obese group presented an increased BMI and waist circumference when compared with the non-obese group $(\mathrm{p}<0.05)$. Table 1 shows the sociodemographic characteristics of the patients.

Table 1. Sociodemographic characteristics of patients.

\begin{tabular}{lccc}
\hline \multicolumn{1}{c}{ Variables } & Non-Obese $(\mathrm{n}=39)$ & Obese (n=55) & $\mathrm{p}$-Value \\
\hline Mean age (SD) & $50.7(7.1)$ & $48.9(7.8)$ & 0.94 \\
Number of men (\%) & $14(35.9)$ & $19(34.5)$ & 0.89 \\
BMI in mean (SE) & $25.8(0.5)$ & $36.12(0.57)$ & $0.001^{*}$ \\
Mean of waist circumference and (SE) & $90.34(1.86)$ & $110.89(1.4)$ & $0.001^{*}$ \\
Number of diabetics (\%) & $2(5.1)$ & $9(16.4)$ & 0.11 \\
Number (\%) of arterial hypertension & $3(7.7)$ & $30(54.5)$ & $0.001^{*}$ \\
Number of smokers (\%) & $5(12.8)$ & $4(7.3)$ & 0.48 \\
\hline
\end{tabular}

*: indicates statistical significance with $\mathrm{p}<0.05$

$\mathrm{n}$ : number; SE: standard error; SD: standard deviation

Clinical and microbiological outcomes are presented separately in another scientific article(20). Briefly, both groups presented similar periodontal disease status at baseline 
(periodontitis stage III or IV) ( $>00.05)$. Briefly, at baseline, obese individuals presented mean values of clinical attachment level (CAL) of $4.03 \pm 0.9$, probing pocket depth (PD) $2.90 \pm 0.3$, gingival index (GI) $0.37 \pm 0.25$ and plaque index (PI) $0.51 \pm 0.36$. Non-obese indivudals presented similar values, being CAL $4.23 \pm 1.2$, PD $2.98 \pm 0.5$, GI $0.32 \pm 0.32$ and PI $0.54 \pm 0.32$. At six months, obese patients presented CAL of $3.61 \pm 1.0$, PD $2.24 \pm 0.4$, GI $0.24 \pm 0.26$ and PI $0.37 \pm 0.21$, whereas non-obese patients presented CAL of $3.64 \pm 1.1$, PD $2.22 \pm 0.5$, GI $0.25 \pm 0.20$ and PI 0.33 \pm 0.23 . Periodontal treatment by OSFMD resulted in significant improvements in all periodontal clinical parameters $(\mathrm{p}<0.05)$, with no statistical difference between groups.

FMD was equally efficient in treating periodontitis in both obese and non-obese patients. No significant changes in total bacterial load were observed between the obese and non-obese groups (Figure 2).

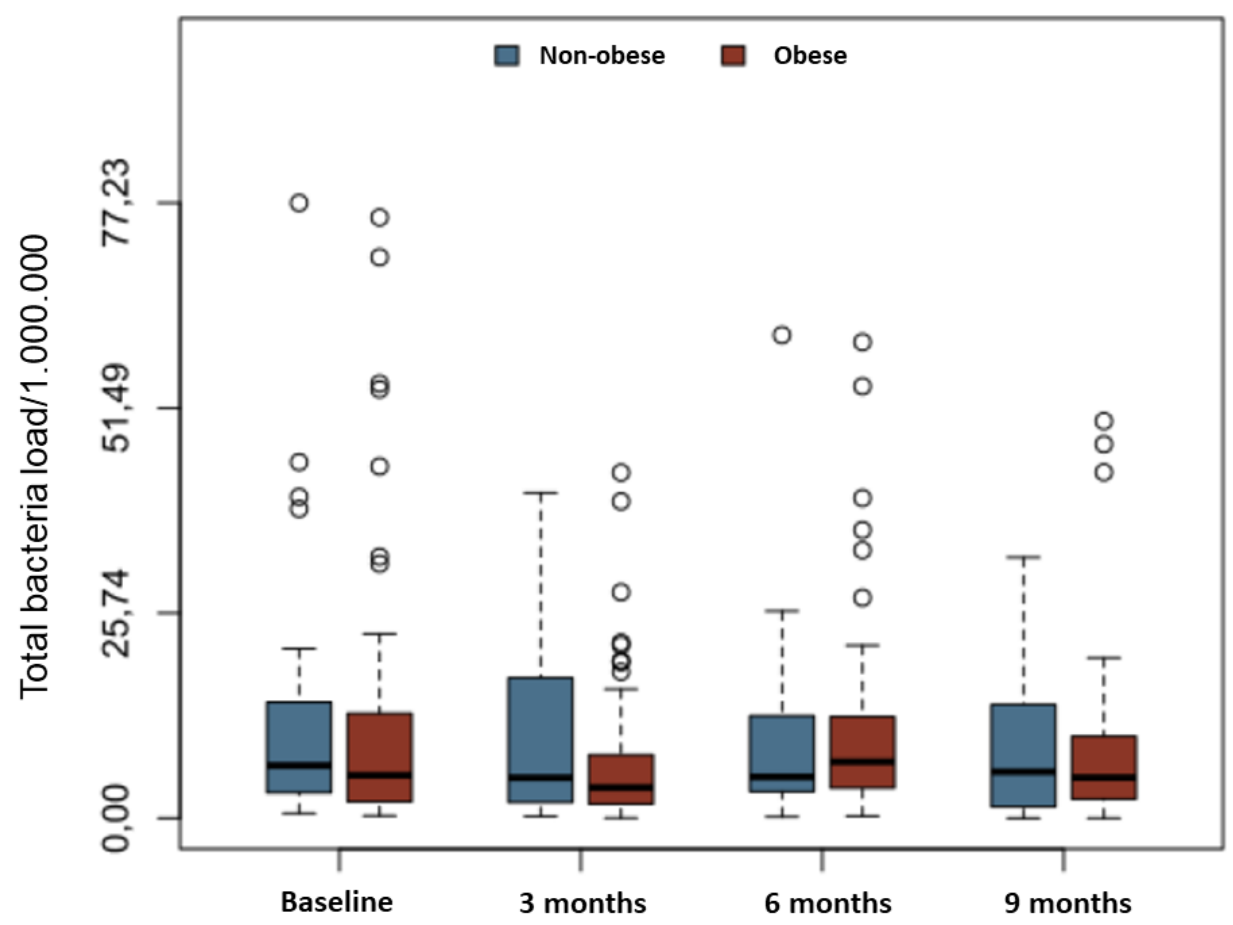

Figure 2. Boxplot showing total bacterial load in obese and nonobese groups at different times

\section{Nitrite results}

At baseline, groups presented similar salivary nitrite levels, with no statistically significant differences $(p>0.05)$. In the non-obese group, FMD protocol resulted in a significant increase $(\mathrm{p}<0.05)$ in salivary nitrite levels by $40 \%$ and $34 \%$ at 6 and 9 months, respectively. In obese individuals, FMD led to an increase in salivary nitrite levels at 6 months $(p<0.05)$; however, at 9 months, the nitrite levels were returned to baseline levels. For both groups, the highest nitrite values were observed at 6 months. There was no significant difference in nitrite levels between groups at 6 and 9 months post treatment (Table 2). 
Table 2. Means (SE) of Salivary Nitrite ( $\mu \mathrm{mol} / \mathrm{L})$ for both groups at baseline and at follow-up visits.

\begin{tabular}{clccc}
\hline Variable & Time point & $\begin{array}{c}\text { Non-Obese } \\
\mathrm{n}=39\end{array}$ & $\begin{array}{c}\text { Obese } \\
\mathrm{n}=55\end{array}$ & $\begin{array}{c}\text { ANOVA } \\
\mathrm{p} \text {-values }\end{array}$ \\
\hline Salivary Nitrite & Baseline & $35.09(5.72)$ & $40.84(5.32)$ & 0.405 \\
& 3 months & $26.50(5.41)$ & $30.36(4.08)$ & 0.602 \\
& 6 months & $59.24(7.46)^{*}$ & $55.74(6.77)^{*}$ & 0.763 \\
& 9 months & $53.35(6.75)^{*}$ & $41.9(4.98)$ & 0.202
\end{tabular}

* indicate significant differences in the same group when compared to baseline $(p<0.05)$.

Impact of FMD on systemic biomarkers in obese and non-obese individuals

Systemic biomarkers were evaluated in obese and non-obese participants at baseline, 3, 6 and 9 months post periodontal therapy. Table 3 depicts the impact of FMD on all the systemic biomarkers studied.

Table 3. Means (SE) of systemic biomarkers for both groups at baseline and at follow-up visits

\begin{tabular}{|c|c|c|c|c|}
\hline Variable & Time point & $\begin{array}{c}\text { Non-Obese } \\
n=39\end{array}$ & $\begin{array}{l}\text { Obese } \\
n=55\end{array}$ & $\begin{array}{l}\text { ANOVA } \\
\text { p-values }\end{array}$ \\
\hline \multirow[t]{4}{*}{ C-Reactive Protein } & Baseline & $1.26(0.16)$ & $1.57(0.11)$ & 0.125 \\
\hline & 3 months & $0.89(0.10)^{*}$ & $1.55(0.12)$ & $0.000^{* *}$ \\
\hline & 6 months & $0.90(0.12)^{*}$ & $1.48(0.16)$ & $0.002^{* *}$ \\
\hline & 9 months & $0.86(0.08)^{*}$ & $1.32(0.12)^{*}$ & $0.001^{* *}$ \\
\hline \multirow[t]{4}{*}{ Fasting blood glucose } & Baseline & $90.74(1.98)$ & $103.17(3.26)$ & $0.000^{* *}$ \\
\hline & 3 months & $91.53(1.97)$ & $104.45(3.18)$ & $0.000^{* *}$ \\
\hline & 6 months & $87.77(1.49)$ & $105.90(3.24)$ & $0.000^{* *}$ \\
\hline & 9 months & $92.06(2.55)$ & $102.16(2.88)$ & $0.003^{* *}$ \\
\hline \multirow[t]{4}{*}{ Alkaline phosphatase } & Baseline & $77.86(4.25)$ & $77.83(2.92)$ & 0.993 \\
\hline & 3 months & $72.03(3.73)^{*}$ & $74.30(3.01)^{*}$ & 0.317 \\
\hline & 6 months & $68.12(4.24)^{*}$ & $73.03(3.20)^{*}$ & 0.793 \\
\hline & 9 months & $70.88(4.35)^{*}$ & $73.77(2.99)^{*}$ & 0.631 \\
\hline
\end{tabular}

\footnotetext{
*: indicate significant differences in the same group when compared with baseline $(\mathrm{p}<0.05)$.

**: indicate significant differences between groups at the same time point $(\mathrm{p}<0.05)$.
}

Obese group presented significantly higher levels of CRP when compared with the nonobese group. Nonsurgical periodontal treatment by FMD resulted in significantly decreased levels of CRP and alkaline phosphatase in both obese and non-obese participants $(\mathrm{p}<0.05)$.

Although the obese group presented increased levels of fasting blood glucose $(p<0.05)$ when compared with the non-obese group, FMD had no impact during follow up time in both groups ( $>0.05)$. 


\section{Discussion}

This study demonstrates that obese patients with periodontitis present similar salivary nitrite levels when compared with non-obese individuals. Periodontal treatment by the FMD protocol resulted in increased salivary nitrite levels in non-obese individuals with periodontitis and a transient increase in obese individuals with no statistical significance between groups during follow-up times. FMD was associated with a decrease in systemic biomarkers related to systemic inflammation and cardiovascular disease, such as CRP and alkaline phosphatase, and had no impact on fasting blood glucose regardless of obesity status.

The proinflammatory state observed in obese individuals leads to an overproduction of reactive oxygen species and hence oxidative stress (21). Nitrite has been strongly correlated with oxidative stress, which is believed to be a meeting point between obesity and periodontitis. Conversely, although we expected higher nitrite levels in obese patients, the present study demonstrated similar salivary nitrite levels between obese and non-obese individuals at baseline.

Obesity has been associated with worse periodontal conditions (22). However, it still remains unclear whether obese individuals have a worse response to periodontal treatment than non-obese individuals (20). In fact, our previous study using this same population (20) revealed no significant differences in the periodontal status of obese and non-obese individuals and no significant differences in periodontal response to FMD. In addition, although we previously demonstrated that FMD decreased specific microbial counts related to periodontitis(20), we presented herein that total bacterial load remained unchanged over follow-up periods. Therefore, the above-mentioned results may explain why obese and non-obese individuals presented similar nitrite levels during follow-ups.

Our results showed that periodontal treatment by FMD increased salivary nitrite levels in non-obese individuals, and in obese individuals, there was a transient increase at 6 months, and baseline levels were re-established at 9 months. These results are in accordance with a study conducted by Ozer et al.(10), which found an increase in salivary nitric oxide levels after periodontal treatment in systemically healthy patients with periodontitis. A previous study by our group(11) showed that salivary nitrite concentrations did not tend to change over time in systemically healthy patients with periodontitis submitted to FMD protocol. In this line, Meschiari et al. (12) observed lower salivary nitrite concentration in periodontitis patients when compared with periodontal healthy individuals, and this situation remained unchanged after periodontal treatment. Thus, despite differences in methodologies, such as follow-up periods, periodontal treatment protocol, and assay method, the present study results and the above-mentioned studies indicate a small impact of periodontal treatment towards increasing salivary nitrite concentration.

Most of the nitrite availability derives from endothelial nitric oxide synthase activity (23). However, nitric oxide synthase-independent factors such as nitrate-rich diet, liver and kidney function, and bowel-derived bacterial nitrate synthesis can also impact nitrate-nitrite concentration (24). Since obese individuals often present several systemic alterations, this fact may explain the transient increase in salivary nitrite levels in this group.

Investigation of the total bacterial load was performed in order to seek an association with its decrease resulted by FMD protocol and lower salivary nitrite concentrations. In this study, total bacterial load tend not to change over follow-up periods; however, it is important to highlight that the bacterial samples were obtained from subgingival sulcus, and specific bacteria species correlated with nitrite production were not evaluated. Therefore, we recommend that future studies should assess bacteria related to nitrite production in salivary samples.

In this study, nonsurgical periodontal treatment through FMD resulted in a decrease in CRP, a protein related to cardiovascular disease (25), regardless of obesity status. This data corroborates findings that show a reduction in CRP serum levels after non-surgical periodontal treatment in obese and non-obese patients with periodontitis (26). Moreover, during the 9-month follow-up in this study, FMD had no impact on fasting blood glucose in both obese and non-obese patients. Our results corroborate the findings of a clinical study that found no statistically significant difference in fasting blood glucose between obese and diabetic obese patients submitted to periodontal therapy by FMD (27). 
The greater considerations on systemic harms associated with the use of mouthwashes need to be further studied to elucidate the impact of the enterosalivary nitrite pathway on insulin resistance and vascular endothelial dysfunction(28). However, this study shows that FMD protocol can be used in obese and non-obese periodontitis patients, providing a positive impact on systemic biomarkers related to inflammation and cardiovascular diseases.

Our results should be carefully interpreted with the following limitations in mind: inclusion of overweight subjects in the non-obese group, and the use of subrogated cardiovascular outcomes. In addition, although fasting blood glucose represents a reliable marker, for long-term assessment of glycemic control, glycated hemoglobin would be a better marker.

In conclusion, periodontal treatment by FMD protocol resulted in increased salivary nitrite levels in non-obese individuals with periodontitis and a transient increase in obese participants. FMD resulted in a decrease in CRP and alkaline phosphatase; however, this treatment had no impact on the fasting blood glucose.

\section{Acknowledgments}

Authors' are grateful to PAM Bucarein - Joinville Basic Health Unit for all support and help allowing this project to be done. A special thanks to the nursing team from PAM Bucarein. The present study was financially supported by CAPES (307034/2015-1)

\section{Resumo}

0 objetivo deste estudo clínico, é avaliar o impacto da desinfecção bucal completa (DBC) nos níveis de nitrito salivar e biomarcadores sistêmicos e sua correlação com a carga bacteriana subgengival total em pacientes obesos e não obesos com periodontite. No total, 94 pacientes ( 55 obesos e 39 não obesos) foram avaliados inicialmente, sete foram perdidos durante o estudo, resultando em 87 indivíduos ao final. Os resultados foram avaliados no início do estudo, 3, 6 e 9 meses após o tratamento periodontal por DBC. Os niveis de nitrito salivar foram determinados usando o reagente de Griess. Amostras de sangue foram coletadas para determinação da Proteína C Reativa (PCR), fosfatase alcalina e glicemia de jejum. A PCR em tempo real foi usada para determinar a carga bacteriana subgengival total. 0 protocolo de $\mathrm{DBC}$ resultou em níveis aumentados de nitrito salivar em 6 e 9 meses após o tratamento no grupo de não obesos $(\mathrm{p}<0,05)$. Em indivíduos obesos, o tratamento da DBC levou a um aumento nos níveis de nitrito salivar em 6 meses $(p<0,05)$; no entanto, aos 9 meses, os níveis de nitrito voltaram aos níveis basais. Para ambos os grupos, os maiores valores de nitrito foram observados aos 6 meses. Além disso, em ambos os grupos, a DBC foi associada à diminuição dos biomarcadores relacionados à inflamação sistêmica e doenças cardiovasculares, como PCR ( $p<0,05)$ e fosfatase alcalina ( $p<0,05)$, e não teve impacto na glicemia de jejum. Este estudo demonstra que pacientes obesos com periodontite apresentam níveis de nitrito salivar semelhantes quando comparados a indivíduos não obesos. 0 protocolo de DBC resultou em aumentos nos níveis de nitrito salivar e foi associado a um impacto positivo nos biomarcadores sistêmicos, independentemente do status de obesidade.

Ethics: ethics committee approval (protocol \# 36828114.4.0000.5501) 


\section{References}

1. Papapanou PN, Sanz M, Buduneli N, Dietrich T, Feres M, Fine DH, et al. Periodontitis: Consensus report of workgroup 2 of the 2017 World Workshop on the Classification of Periodontal and Peri-Implant Diseases and Conditions. J Clin Periodontol. 2018;45(March):S162-70.

2. Mark Bartold P, Van Dyke TE. Host modulation: controlling the inflammation to control the infection. Periodontol 2000. 2017;75(1):317-29.

3. Kendall HK, Marshall RI, Bartold PM. Nitric oxide and tissue destruction. Oral Dis. 2001;7(1):210.

4. Korhonen R, Lahti A, Kankaanranta H, Moilanen E. Nitric oxide production and signaling in inflammation. Curr Drug Targets Inflamm Allergy. 2005;4(4):471-9.

5. Lundberg J0, Weitzberg E, Cole JA, Benjamin N. Nitrate, bacteria and human health. Nat Rev Microbiol. 2004;2(7):593-602.

6. Lundberg J0, Weitzberg E, Gladwin MT. The nitrate-nitrite-nitric oxide pathway in physiology and therapeutics. Nat Rev Drug Discov. 2008;7(2):156-67.

7. Parwani SR, Chitnis PJ, Parwani RN. Salivary nitric oxide levels in inflammatory periodontal disease - A case-control and interventional study. Int J Dent Hyg. 2012;10(1):67-73.

8. Reher VGS, Zenóbio EG, Costa F0, Reher P, Soares R V. Nitric oxide levels in saliva increase with severity of chronic periodontitis. J Oral Sci. 2007;49(4):271-6.

9. Aurer A, Aleksić J, Ivić-Kardum M, Aurer J, Čulo F. Nitric Oxide synthesis is decreased in periodontitis. J Clin Periodontol. 2001;28(6):565-8.

10. Ozer L, Elgun S, Ozdemir B, Pervane B, Ozmeric N. Arginine-nitric oxide-polyamine metabolism in periodontal disease. J Periodontol [Internet]. 2011;82(2):320-8. Available from: http://eutils.ncbi.nlm.nih.gov/entrez/eutils/elink.fcgi?dbfrom=pubmed\&tid=208313694tretmode=re fetcmd=prlinks\%5Cnpapers2://publication/doi/10.1902/jop.2010.100199

11. Cortelli SC, Costa FO, Rodrigues E, Cota LOM, Cortelli JR. Periodontal Therapy Effects on Nitrite Related to Oral Bacteria: A 6-Month Randomized Clinical Trial. J Periodontol. 2015;86(8):984-94.

12. Meschiari CA, Zuardi LR, Gomes VA, Costa de Almeida GR, Novaes AB, Gerlach RF, et al. Salivary, blood and plasma nitrite concentrations in periodontal patients and healthy individuals before and after periodontal treatment. Clin Chim Acta [Internet]. 2015;444:293-6. Available from: http://dx.doi.org/10.1016/j.cca.2015.02.045

13. Modin A, Björne H, Herulf M, Alving K, Weitzberg E, Lundberg JON. Nitrite-derived nitric oxide: A possible mediator of "acidic-metabolic" vasodilation. Acta Physiol Scand. 2001;171(1):916.

14. Kapil V, Haydar SMA, Pearl V, Lundberg JO, Weitzberg E, Ahluwalia A. Physiological role for nitrate-reducing oral bacteria in blood pressure control. Free Radic Biol Med [Internet]. 2013;55:93100. Available from: http://dx.doi.org/10.1016/j.freeradbiomed.2012.11.013

15. Ghasemi A, Jeddi S. Anti-obesity and anti-diabetic effects of nitrate and nitrite. Nitric Oxide - Biol Chem [Internet]. 2017;70(24):9-24. Available from: https://doi.org/10.1016/j.niox.2017.08.003

16. Joshipura KJ, Muñoz-Torres FJ, Morou-Bermudez E PR. Over-the-counter mouthwash use and risk of pre-diabetes/diabetes. Nitric 0xide. 2017;71:14-20.

17. Quirynen M, Bollen CML, Vandekerckhove BNA, Dekeyser C, Papaioannou W, Eyssen H. Fullvs. Partial-mouth Disinfection in the Treatment of Periodontal Infections: Short-term Clinical and Microbiological Observations. J Dent Res. 1995; 
18. Tonetti MS, Greenwell H, Kornman KS. Staging and grading of periodontitis: Framework and proposal of a new classification and case definition. J Periodontol. 2018;89(February):S159-72.

19. Araujo MWB, Benedek KM, Benedek JR, Grossi SG, Dorn J, Wactawski-Wende J, et al. Reproducibility of Probing Depth Measurements Using a Constant-Force Electronic Probe: Analysis of Inter- and Intraexaminer Variability. J Periodontol. 2003;

20. Peralta S, Cortelli SC, Rovai ES, Miranda TB, Costa F0, Cortelli JR. Clinical and microbiological evaluation of non-surgical periodontal therapy in obese and non-obese individuals with periodontitis : a 9-month prospective longitudinal study Abstract. 2020;1-9.

21. Dursun E, Akalin FA, Genc T, Cinar N, Erel 0, Yildiz B0. Oxidative stress and periodontal disease in obesity. Med (United States). 2016;95(12):1-7.

22. Kang J, Smith S, Pavitt S, Wu J. Association between central obesity and tooth loss in the non-obese people: Results from the continuous National Health and Nutrition Examination Survey (NHANES) 1999-2012. J Clin Periodontol. 2019;46(4):430-7.

23. Rhodes PM, Leone AM, Francis PL, Struthers AD, Moncada S. The L-arginine: Nitric oxide pathway is the major source of plasma nitrite in fasted humans. Biochem Biophys Res Commun. 1995;

24. Lauer T, Preik M, Rassaf T, Strauer BE, Deussen A, Feelisch M, et al. Plasma nitrite rather than nitrate reflects regional endothelial nitric oxide synthase activity but lacks intrinsic vasodilator action. Proc Natl Acad Sci U S A. 2001;

25. Yu T, Zhao L, Huang X, Xie M, Wang X, Ma C, et al. Postoperative Weight Loss Masks Metabolic Impacts of Periodontitis in Obese Rodents. J Periodontol. 2017;88(6):e97-108.

26. Maria de Souza G, Willya Douglas de Oliveira D, Santos Lages F, Andrade Fernandes I, Gabriel Moreira Falci S. Relationship between bariatric surgery and periodontal status: a systematic review and meta-analysis. Surg Obes Relat Dis [Internet]. 2018;14(8):1205-16. Available from: https://doi.org/10.1016/j.soard.2018.04.018

27. Taşdemir Z, Taşdemir F Ozsarı, Koçyiğit i, Yazıcı C, Gurgan CA. The clinical and systemic effects of periodontal treatment in diabetic and non-diabetic obese patients. J Oral Sci. 2016;58(4):523-31.

28. Kobayashi J, Ohtake K, Uchida H. No-rich diet for lifestyle-related diseases. Nutrients. 2015;7(6):4911-37. 